\title{
Ortaöğretim Öğrencilerinin Okul Tükenmişliği ve Okula Yabancılaşma Algıları Arasındaki ílişkisinin İncelenmesi
}

\section{Analysis of the Relationship between Secondary Education Students' School Burnout and Perceptions Regarding Alienation to School}

\author{
Ebru KÜLEKÇi AKYAVUZ ${ }^{1}$
}

\section{Öz}

Bu çalışmanın amacı ortaöğretim öğrencilerinin okula yabancılaşma algılarını ve tükenmişlik algılarının belirleyerek bu iki algı arasındaki ilişkinin düzeyinin ve yönünü ortaya koymaktır. Araştırma nicel araştırma yöntemlerinden ilişkisel tarama modeli olarak tasarlanmıştır. Çalışmanın evrenini 2018-2019 eğitim öğretim yılında Kilis il merkezinde eğitim gören ortaöğretim öğrencileri oluşturmaktadır. Toplamda 450 öğrenci örnekleme dâhil edilmiştir ancak asıl çalışma 367 öğrenci üzerinden gerçekleştirilmiştir. Verilerin analizinde aritmetik ortalama, Pearson Korelasyon katsayısı ve çoklu regresyon analizi yapılmıştır. Araştırmada kişisel bilgi formu, "okul tükenmişliği ölçeği" ve "öğrenci yabancılaşma ölçeği" olmak üzere 3 veri toplama aracı kullanılmıştır. Yapılan analizler sonucunda örnekleme dâhil olan ortaöğretim öğrencilerinin okul tükenmişliği düzeylerinin orta seviyede olduğu alt boyutlarında ise duygusal tükenme alt boyutunun orta düzeyde; duyarsızlaşma ve düşük kişisel başarı alt boyutlarının ise düşük düzeyde olduğu sonucuna ulaşılmıştır. Ortaöğretim öğrencilerinin okula yabancılaşma puan ortalamalarının düşük seviyede olduğu tespit edilmiştir. Okul tükenmişliği ile Güçsüzlük, Kuralsızlık, Soyutlanmışık, Anlamsızlık ve Okula yabancılaşma arasında pozitif yönlü anlamlı bir ilişki olduğu sonucuna ulaşılmıştır.

Anahtar Kelimeler: Ortaöğretim, okula yabancılaşma, okul tükenmişliği, öğrenci

\section{Abstract}

The aim of this study is to identify the students' perception regarding alienation and burn out to school and display the level and direction of the relationship between these two perceptions. The study was designed as a correlational survey model among quantitative research methods. The population of the study is composed of secondary education students in Kilis city center in 2018-2019 academic year. 450 students in total were involved in the sampling but the main study was conducted over 367 students. Arithmetical average, Pearson correlation coefficient and multiple regression analysis were performed in the analysis of the data. 3 data collection tools in total were used in the study as personal information form, "school burnout scale" and "student alienation scale". As the result of the analyses conducted, it was concluded that school burnout level of secondary education students involved in the sampling was to be medium, while in sub dimensions emotional burnout was to be medium; the level of desensitisation and low personal success sub levels were found to be low. It was found that secondary education students' alienation to school point average was low. It was found that there was a significant relationship in the positive direction among school burnout and powerlessness, irregularity, isolation, meaninglessness and alienation to school.

Keywords: Secondary education, alienation to school, school burnout, student 


\section{Extended Abstract}

Introduction: Along with globalization, social, political and economic changes in the social structure expose students to multiple negative situations such as stress, emotional unbalance and alienation related to academic pressure, emotional stress, role confusion and high expectations (Huang \& Lin, 2010: 2). This situation can be observed widely in our country. Our education system is structured around exams based on high level competition during primary, middle, high school levels. Therefore, planning a career for students in these levels of education is most of the time becomes troublesome and stressful (Çapri, Gündüz, \& Gökçakan, 2011). The long periods the students spend in education institutions and lessons being too intensive can lead to burnout syndrome and alienation to school for students. The aim of this study is to identify the students' perception regarding alienation and burn out to school and display the level and direction of the relationship between these two perceptions. With this aim, main problematic of the study is as follows:

- Is perception regarding alienation to school of secondary education students a meaningful precursor of burnout perceptions? Problems below in the direction of the main problem are identified.

- What are the perceptions of secondary education students regarding school burnout and sub dimensions?

- What are the perceptions of secondary education students regarding alienation to school and its sub dimensions?

- Is there a significant relationship between the school alienation points and alienation to school's sub dimensions?

Method: The study was designed as a correlational survey model among quantitative research methods. In this study, since it is aimed to identify the level of the relationship between alienation to school and perceptions regarding burnout, correlational survey model is selected.

The population of the study is composed of secondary education students in Kilis city center in 2018-2019 academic year. Sampling selection is conducted on the basis of the population. Stratified sampling is preferred during sampling selection. 450 students in total were involved in the sampling but the main study was conducted over 367 students. Arithmetical average, Pearson correlation coefficient and multiple regression analysis were performed in the analysis of the data. 3 data collection tools in total were used in the study as personal information form, "school burnout scale" and "student alienation scale".

Results: The results obtained from the sampling of involved secondary education students were as follows; School Burnout level $(X=2,63)$ was found to be at medium level, in the sub dimensions of Emotional Burnout sub-dimension level $(X=2,90)$ was at medium level, sub-dimensions Desensitisation $(X=2,34)$ and Low Personal Success $(X=2,51)$ level were found to be mid-scale. It was found that secondary education students' alienation to school point average $(X=2,52)$ was low. When sub dimensions of alienation to school were examined Powerlessness $(X=2,38)$ and Meaninglessness $(X=2,30)$ sub-dimensions were found to be low while Irregularity $(X=2,78)$ and Meaninglessness $(X=2,61)$ sub-dimensions were at medium level.

It was concluded that there was a significant positive relationship among school burnout and powerlessness ( $r=.344, p<.01)$, Irregularity $(r=.474, p<.01)$, Isolation $(r=.418, p<.01)$, Meaninglessness $(r=.508, p<.01)$ and alienation to school $(r=.612, p<.01)$. As a result of multiple regression analysis, as sub dimensions of alienation to school; powerlessness, irregularity, isolation and meaninglessness had a significant relationship to secondary education students' school burnout $(R=0.616, R 2=0.379, p<0.01)$. Sub dimensions of powerlessness, irregularity, isolation and meaninglessness explain $38 \%$ of school burnout.

Conclusion: As the result of the analyses conducted, it was concluded that school burnout level of secondary education students involved in the sampling was to be medium, while in sub dimensions emotional burnout was to be medium; the level of desensitisation and low personal success sub levels were found to be low. The results of the study showed parallel characteristics with the literature (Balkıs, Duru, Buluş, \& Duru, 2011; Baş, 2012; Chang, Rand, \& Strunk, 2000; Cushan \& West, 2006; Çapulcuğlu \& Gündüz, 2013; Hu \& Schaufeli, 2009; Kara, 2014; Kutsal, 2009; Lingard, 2007; Polat, 2018; Salmela-Aro et al., 2009; SalmelaAro \& Upadyaya, 2014; Schaufeli \& Salanova, 2007; Yang, 2004). It was noted that getting ready for university exams, the lessons being intensive, high expectations by close contacts rendered emotions related to burnout inevitable for secondary education students.

According to the analyses conducted in second sub-problem, it was found that secondary education students' alienation to school point average was low. When sub dimensions of alienation were examined, powerlessness and meaninglessness sub dimensions were found to be low whereas irregularity and isolation were at medium level. The results of the study showed parallel characteristics with the literature (Arastaman, 2009; Coşkun \& Altay, 2009, Katıtaş, 2012; Polat, 2018).

As the result of the analyses conducted to identify whether there was a significant relationship between school burnout, along with alienation to school and sub dimensions of alienation to school; it was found that there was a significant relationship in the positive direction among school burnout and powerlessness, irregularity, isolation, meaninglessness and alienation to school. Multiple regression analysis revealed that powerlessness, irregularity, isolation, meaninglessness sub dimensions of alienation to school had a significant relationship with secondary education students' school burnout. Powerlessness, irregularity, isolation, meaninglessness sub dimensions of alienation to school explained $38 \%$ of school burnout. It could be noted that alienation to school is a significant precursor of school burnout. In other words, as secondary education students' school burnout 
increases, alienation to school will increase accordingly. This result was found to be in consistency with the relevant studies in the literature (Atik, 2016; Coşkun \& Altay, 2009; Katıtaş, 2012; Lin \& Huang, 2012; Polat, 2018; Tümkaya, 2016).

The study examined the relationship between alienation to school and school burnout of secondary education students. The following recommendations were presented to the researchers and implementers in line with the results obtained in the study:

- The study has noted that alienation to school is an important precursor of school burnout. School principals' and teachers' designing activities aiming to improve students' sense of belonging to school is important. Especially, the number of activities that would enable students to transfer the information acquired at the school to their daily lives should be increased.

- Educational programmes aiming to reduce alienation to school and school burnout of secondary education students could be prepared. 


\section{Giriş}

Küreselleşme süreci ile birlikte toplumda yaşanan sosyal, politik ve ekonomik değiş̧imler, okuldaki öğrencileri akademik baskı, duygusal stres, rol karmaşası, yüksek beklentilere bağlı stres, duygusal dengesizlik ve yabancılaşma gibi birçok olumsuz durum ile karşı karşıya bırakmaktadır (Huang \& Lin, 2010: 2). Türkiye'de de öğrencilerde görülen bu olumsuz durumlar fazlası ile söz konusudur. Türk eğitim sistemi, ilkokul, ortaokul, lise dönemlerinde yüksek seviyede yarışmaya dayalı sınavların olduğu bir yapıya sahiptir. Bu sebeple bu öğretim kademelerinde bulunan öğrenciler için gelecekteki kariyerlerini planlamak genellikle sıkıntılı ve stresli durum haline gelmektedir (Çapri, Gündüz, \& Gökçakan, 2011). Öğrencilerin eğitim kurumlarında geçirdikleri sürenin fazla olması, derslerin yoğunlukta olması öğrencilerde tükenmişliğe ve okula karşı yabancılaşma duygularının artmasına neden olabilmektedir.

Tükenmişlik, yıpranma, enerji kaybı, zayıflama, yorgunluk ve huzursuzluk şeklinde kendini gösteren fiziksel veya psikolojik bir sendromdur (Maslach \& Lieter, 2016). Tükenmişlik kavramı her ne kadar işgörenlerle ilgili bir kavram olsa da son zamanlarda öğrenciler için de kullanılmaktadır. Öğrenciler de eğitim sistemi içerisinde bazı görev ve sorumlulukları yerine getirmek zorundadırlar. Örneğin, sınavlarını ve sınıflarını geçmek için okula devam etmeleri ve kendilerine verilen ödevleri yapmaları zorunludur (Salmelo-Aro, Savolainen, \& Holopainen, 2009). Bu görev ve sorumlulukların öğrencilerin beklentilerinden fazla olması ve öğrenciler tarafından karşılanamaması tükenmişliğe yol açmaktadır. Öğrencilerle ilgili yapılan çalışmalarda tükenmişlik "okul tükenmişliği" veya "öğrenci tükenmişliği" şeklinde isimlendirilmiştir (Aypay \& Eryılmaz, 2011; Chang, Rand, \& Strunk, 2000; Çapri, Gündüz, \& Gökçakan, 2011; Çapulcuoğlu, 2012; Hu \& Schaufeli, 2009; Gündüz, Çapri,\& Gökçakan, 2012; Meier \& Schmeck, 1985; Yang, 2004; Yang \& Farn, 2005). Okul tükenmişliği, ders taleplerinin fazla olmasından dolayı tükenmiş hissetme, ders ve sorumluluklarından uzaklaşma ve ilgilenmeme, derslerde aktif olmama veya kendini değersiz hissetme şeklinde yaşanan bir kavram olarak tanımlanmaktadır (Schaufeli, Martinez, Marques-Pinto, Salanova, \& Bakker, 2002). Okul tükenmişliği, öğrencinin kendisinden beklenen başarıyı karşılayamadığı durumlarda gözlemlenen bir gerginlik hali olarak değerlendirilmektedir (Barnett \& Flores, 2016). Özetle ifade etmek gerekirse okul tükenmişliği, öğrencinin eğitim öğretim faaliyetlerini olumsuz yönde etkilediği söylenebilir. Okul tükenmişliği düşük akademik başarı, kaygı, depresyon, psikolojik problemler, devamsızık, okulu bırakma (Yang, 2004) şeklinde kendini gösterebilmektedir.

Öğrencilerin okul tükenmişliği yaşamalarının birçok nedeni vardır. Öğrencilerin okullarda yaşadıkları tükenmişlik duygularının başlıca nedenleri, öğrencinin kendi beklentileri ile ailesi, arkadaşları ve öğretmenlerinden oluşan yakın çevresinin beklentileri arasındaki uyumsuzluklar (Kiuru, Aunola, Nurmi, Leskinen, \& Salmela-Aro, 2008; Nedim-Bal \& Kaya, 2017; Salmela-Aro, Kiuru, Leskinen, \& Nurmi, 2009;), ders yükünün veya sorumluluklarının fazla olması, (NedimBal \& Kaya, 2017; Salanova, Schaufeli, Martizena, \& Breso, 2009), sınav baskısı (Salanova vd., 2009) şeklinde sıralanmaktadır.

Okul tükenmişliğinin okula devam etmeme, derslere motive olamama, okul bırakma oranının yüksekliği, düşük akademik başarı, depresyon, eğitimde gecikmeler gibi birtakım sonuçlara yol açtığı görülmektedir (Aypay \& Eryılmaz, 2011; Schaufeli vd., 2002; Salmela-Aro, Savolainen, \& Holopainen, 2009). Tükenmişlik düzeyi yüksek olan öğrencilerde gözlemlenebilecek sorunlardan biri de okula yabancılaşmadır. Okula yabancılaşma öğrencilerin diğer öğrencilere, öğretmenlere, okulun çevresine ve yapısına bağlıı̆̆ın olmayışıdır (Warner, Weist, \& Krulak, 1999). Schulz ve Rubel (2011) tarafından okula yabancılaşma, öğrencinin okul ortamından akademik ve sosyal açıdan uzaklaşması olarak tanımlanmıştır. Sidorkin (2004)'e göre okula yabancılaşma; öğrencilerin öğrenmeyle ilgili süreçlerden uzaklaşması, bu süreçlerin giderek bireylerde bir anlam ifade etmemesi, öğrenciler için eğitimin sıkıcı, zevksiz ve monoton bir hale gelmesi ve öğrenmeye ve öğretmeye karşı ilginin giderek azalması ile sonuçlanan bir durumu ifade etmektedir. Yapılan tanımlar dikkate alındığında okula yabancılaşmanın öğrencinin okulla ilgili faaliyetlerden uzaklaşması şeklinde tanımlamak mümkündür. Bir öğrencinin okula yabancılaşmasında birçok faktör söz konusudur. Kunkel, Thampson ve Mcelhinney (1973) öğrencilerin okula yabancılaşmalarının nedenlerini öğrencilerin okulla gerçek hayat arasında bağlantı kuramamaları, öğretmenlerin öğrencilere ilgi ve anlayış göstermemeleri, velilerin öğrencileri yeterince desteklememeleri, öğrencilerin kendi hayatları kontrol edememeleri ve okul kurallarının katı bir şekilde düzenlemeleri şeklinde belirtmişlerdir. Hascher ve Hagenauer (2010) ise okula yabancılaşmanın öğrencilerin okula karşı yeterli seviyede güdülenmemelerinden kaynaklandığını vurgulamışlardır. Bu sıralanan sebeplerden ötürü öğrenciler eğitim öğretim faaliyetlerinden uzaklaşarak yabancılaşmaktadırlar. Eğitim ve öğretim etkinliklerine yabancılaşan öğrenci dersin içeriğini çoğunlukla öğretmene yönelik olarak algılamakta ve bu sebeple derse odaklanmakta zorluk yaşamaktadır. Öğrenci konu ile toplumsal çevre arasında bağlantı kurmakta zorlanmaktadır (Şimşek, Abuzar, Yegin, Şimşek, \& Demir, 2015). Bu durum öğrencilerin kendilerini okul hayatından soyutlayarak hem okula yabancılaşmalarına hem de tükenmişlik davranışları sergilemelerine de neden olmaktadır. 
Alanyazın incelendiğinde okul tükenmişliği (Aypay \& Eryılmaz, 2011; Çapri, Gündüz, \& Gökçakan, 2011; Gündüz, Çapri, \& Gökçakan, 2012; Çapri \& Yedigöz-Sönmez, 2013; Çapulcuoğlu, 2012; Hu \& Schaufeli, 2009; Jacobs \& Dodd, 2003; Kiuru vd., 2008; Kutsal \& Bilge, 2012; Lingard, 2007; Meier \& Schmeck, 1985; Rostami, Abedi, \& Schaufeli, 2012; Yang, 2004; Salmala-Aro, Kiuru, \& Nurmi, 2008; Schaufeli \& Salanova, 2007; Yang \& Farn, 2005; Zhang, Gan, \& Zhang, 2005) ve okula yabancılaşma (Çelik, 2005; Duru, 1995; Katıtaş, 2012; Sungur, 2013; Türk, 2010; Türk, 2013; Yiğit, 2010; Yüksel, 2006) ile ilgili alanyazında farklı eğitim seviyelerinde çalışmaların yapıldığı görülmektedir. Ancak öğrencilerin okul tükenmişliği ve okula yabancılaşmalarını inceleyen sınırlı sayıda çalışmanın mevcut olduğu görülmektedir (Huang \& Lin, 2010; Polat, 2018; Tümkaya, 2016). Yapılan bu çalışma özellikle üniversiteye geçme aşamasında önemli bir sınavla karşı karşıya kalan ortaöğretim öğrencilerinin okul tükenmişliği ve okula yabancılaşma algıları arasındaki ilişkiyi belirleyerek alanyazındaki eksikliği gidereceği için önem arz etmektedir.

\section{Çalışmanın Amacı}

$\mathrm{Bu}$ çalışmanın amacı ortaöğretim öğrencilerinin okula yabancılaşma algılarını ve tükenmişlik algılarının belirleyerek bu iki algı arasındaki ilişkinin düzeyini ve yönünü ortaya koymaktır. Bu amaç doğrultusunda çalışmanın ana problemi şu şekildedir:

Ortaöğretim öğrencilerinin okula yabancılaşma algıları tükenmişlik algılarının anlamlı bir yordayıcısı mıdır? Ana problem doğrultusunda aşağıdaki alt problemler belirlenmiştir?

- Ortaöğretim öğrencilerinin okul tükenmişliğine ve alt boyutlarına yönelik algıları nelerdir?

- Ortaöğretim öğrencilerinin okula yabancılaşma ve alt boyutlarına yönelik algıları nelerdir?

- Ortaöğretim öğrencilerinin okul tükenmişliği puanları ile okula yabancılaşma alt boyutları arasında anlamlı bir ilişki var mıdır?

\section{Yöntem}

\section{Araştırma Modeli}

Araştırma nicel araştırma yöntemlerinden ilişkisel tarama modeli olarak tasarlanmıştır. Karasar (2009)'a göre ilişkisel tarama modeli, iki veya daha çok değişken arasında birlikte değişimin varlığını veya derecesini belirlemeyi amaçlayan araştırma modelidir. Bu çalışmada da ortaöğretim öğrencilerinin okula yabancılaşma ve tükenmişlik algıları arasındaki ilişkinin ne derecede olduğunu belirlemek amaçlandığı için ilişkisel tarama modeli tercih edilmiştir.

\section{Evren Örneklem}

Çalışmanın evrenini 2018-2019 eğitim öğretim yılında Kilis il merkezinde eğitim gören ortaöğretim öğrencileri oluşturmaktadır. Evren üzerinden örneklem seçimine gidilmiştir. Örneklem seçilirken tabakalı örnekleme yöntemi tercih edilmiştir. Tabakalı örnekleme, evrendeki alt grupların belirlenerek bunların evren büyüklüğündeki oranları ile örneklemde temsil edilmelerini sağlayan örnekleme yöntemidir (Büyüköztürk, Çakmak, Akgün, Karadeniz, \& Demirel, 2010). Örneklem seçiminde liseler fen lisesi, Anadolu lisesi ve meslek lisesi olmak üzere 3 lise türü olarak tabakalara ayrılmış ve bu tabakalardan eşit oranda öğrenci seçilmiştir. Toplamda 450 öğrenci örnekleme dâhil edilmiştir. Ölçme araçlarının uygulamasında 409 öğrenciye ait verilerden geri dönüş sağlanmıştır. 409 öğrencinin verilerinden eksik veya rastgele dolduran öğrencilerin verileri iptal edilerek asıl çalışma 367 öğrenci üzerinden gerçekleştirilmiştir. Örnekleme dâhil olan ortaöğretim öğrencilere ait demografik bilgiler aşağıdaki tabloda verilmiştir.

Tablo 1. Ortaöğretim öğrencilerine ait demografik bilgiler

\begin{tabular}{llll}
\hline Değişken & Gruplar & N & $\%$ \\
\hline Cinsiyet & Kadın & 213 & 58 \\
& Erkek & 154 & 42 \\
Sınıf Düzeyi & 9. sınıf & 164 & 44,7 \\
& 10. sınıf & 101 & 27,5 \\
& 11. sınıf & 102 & 27,8 \\
Ortaöğretim Türü & Anadolu Lisesi & 148 & 40,3 \\
& Fen Lisesi & 108 & 29,4 \\
& Meslek Lisesi & 111 & 30,2 \\
\hline
\end{tabular}


Tablo 1'de katılımcılara ait demografik bilgiler yer almaktadır. Katılımcıların \%58'inin kadın, \%42'sinin erkek öğrencilerin olduğu; sınıf dağılımında ise çoğunluk olarak 9. sınıf $(\% 44,7)$ öğrencilerinin yer aldığı görülmektedir. Ortaöğretim türünde Anadolu Lisesi öğrencilerinin \%40,3, Fen Lisesi öğrencilerinin \%29,4 ve Meslek Lisesi öğrencilerinin oranının \%30,2 olduğu görülmektedir.

\section{Veri Toplama Araçları}

Araştırmada kişisel bilgi formu, "okul tükenmişliği ölçeği" ve "öğrenci yabancılaşma ölçeği” olmak üzere 3 veri toplama aracı kullanılmıştır.

\section{Kişisel Bilgi Formu}

Araştırmacı tarafından oluşturulan kişisel bilgi formu ortaöğretim öğrencilerinin cinsiyet, yaş, sınıf, ailevi bilgilerinin içeren sorulardan oluşmaktadır.

\section{Okul Tükenmişliği Ölçeği}

Ortaokul ve ortaöğretim öğrencilerinin okul ortamlarına bağlı olarak oluşan tükenmişlik durumlarını ölçmek amacıyla Salmela-Aro ve diğ. (2009) tarafından geliştirilen ve Seçer, Halmatov, Veyis, \& Ateş (2013) tarafından Türkçeye uyarlaması yapılan "Okul Tükenmişliği Ölçeği" kullanılmıştır. Ölçek duygusal tükenmişlik, duyarsızlaşma ve düşük kişisel başarı algısı olmak üzere 3 alt boyuttan oluşmaktadır. Ölçek, Hiç Katılmıyorum (1) Katılmıyorum (2), Kısmen Katılıyorum (3), Katılıyorum (4) ve Tamamen Katılıyorum (5) ifadelerinden oluşan 5'li likert tipi olarak derecelendirilmiştir. Ölçeğin Cronbach Alpha katsayısı .86 olarak hesaplanmıştır.

\section{Öğrenci Yabancılaşma Ölçeği}

Okula yabancılaşma ölçeği öğrenci yabancılaşma düzeyini belirlemeye yönelik olarak Çağlar (2012) tarafından geliştirilmiştir. Ölçek güçsüzlük, kuralsızlık, anlamsızlık ve soyutlanmışlık olmak üzere 4 alt boyut ve 20 sorudan oluşmaktadır. 5'li likert tipi olarak hazırlanan ölçek “(1) Kesinlikle katılmıyorum, (2) Katılmıyorum, (3) Kararsızım, (4) Katılıyorum, (5) Kesinlikle katılıyorum" şeklinde derecelendirilmiştir. Yapılan bu çalışma için ölçeğin Cronbach Alpha katsayısı .83 olarak hesaplanmıştır.

\section{Verilerin Analizi}

Verilerin analizinde SPSS 21 paket program kullanılmıştır. Ortaöğretim öğrencilerinin okula yabancılaşma, okul tükenmişlik ve alt boyutlarına yönelik algıları aritmetik ortalama hesaplanarak belirlenmiştir. Aritmetik ortalama puanları düzey şeklinde karşılaştııılmıştır. Puan aralıkları şu şekilde belirlenmiştir: 1.00-1,79 "Çok Düşük", 1.80-2,59 "Düşük", 2,60-3.39 "Orta", 3.40-4.19 "Yüksek" ve 4.20-5.00 "Çok Yüksek". Verilerin normal dağılıp dağılmadığını incelemek amacıyla Kurtosis ve ve Skewness değerleri hesaplanmıştır. Skewness değeri .458 ile .480 arasında Kurtosis değeri ise - .238 ile -.467 arasında değiştiği sonucuna ulaşılmıştır. Skewness ve Kurtosis değerleri -1.5 ile +1.5 aralığında olduğunda normal dağılım gösterdiği kabul edilmektedir (Tabachnick \& Fidell, 2013). Ortaöğretim öğrencilerinin okula yabancılaşma ve okul tükenmişlik puanları arasında anlamlı bir ilişkinin olup olmadığını belirlemek amacıyla Pearson Korelasyon katsayısı hesaplanmıştır. Öğrencilerin okula yabancılaşma algılarının okul tükenmişliği algılarını ne derece yordadığını tespit etmek amacıyla çoklu regresyon analizi yapılmıştır.

\section{Bulgular ve Yorum}

Araştırmanın birinci alt problemi doğrultusunda ortaöğretim öğrencilerinin okul tükenmişliği ve alt boyutlarına yönelik puanları analiz edilmiştir. Elde edilen bulgular Tablo 2' de verilmiştir.

\section{Tablo 2. Ortaöğretim öğrencilerinin okul tükenmişliği ve alt boyutlarına ilişkin puan ve düzeyleri}

\begin{tabular}{lcccc}
\hline Değişkenler & $\mathbf{N}$ & $\overline{\mathbf{X}}$ & ss & Düzey \\
\hline Okul Tükenmişliği & 367 & 2,63 & .915 & Orta \\
Duygusal Tükenme & 367 & 2,90 & .933 & Orta \\
Duyarsızlaşma & 367 & 2,34 & 1.10 & Düşük \\
Düşük Kişisel Başarı & 367 & 2,51 & 1.09 & Düşük \\
\hline
\end{tabular}

Tablo 2'de ortaöğretim öğrencilerinin okul tükenmişliği ve alt boyutlarına yönelik puan ortalamaları verilmiştir. Örnekleme dâhil olan ortaöğretim öğrencilerinin Okul Tükenmişliği düzeylerinin $(\bar{X}=2,63)$ orta seviyede olduğu alt boyutlarında ise Duygusal Tükenme alt boyutunun $(\bar{X}=2,90)$ orta düzeyde; Duyarsızlaşma $(\bar{X}=2,34)$ ve Düşük Kişisel Başarı $(\bar{X}=2,51)$ alt boyutlarının ise düşük düzeyde olduğu bulgusuna ulaşıımıştır. 
Araştırmanın ikinci alt problemi doğrultusunda araştırmaya katılan ortaöğretim öğrencilerinin okula yabancılaşma düzeyleri ve okula yabancılaşmanın alt boyutlarındaki düzeyler belirlenmiştir. Analiz sonucu edinilen bulgular Tablo 3'te gösterilmektedir.

Tablo 3. Ortaöğretim öğrencilerinin okula yabancılaşma ve alt boyutlarına ilişkin puan ve düzeyleri

\begin{tabular}{lcccc}
\hline Değişkenler & $\mathbf{N}$ & $\overline{\mathbf{X}}$ & ss & Düzey \\
\hline Okula Yabancılaşma & 367 & 2,52 & .733 & Düşük \\
Güçsüzlük & 367 & 2,38 & .938 & Düşük \\
Kuralsızlık & 367 & 2,78 & 1.10 & Orta \\
Soyutlanmışlık & 367 & 2,61 & 1.00 & Orta \\
Anlamsızlık & 367 & 2,30 & 1.03 & Düşük \\
\hline
\end{tabular}

Tablo 3 incelendiğinde ortaöğretim öğrencilerinin okula yabancılaşma puan ortalamalarının $(\bar{X}=2,52)$ düşük seviyede olduğu tespit edilmiştir. Okula yabancılaşma alt boyutları incelendiğinde Güçsüzlük $(\bar{X}=2,38)$ ve Anlamsızlık $(\bar{X}=2,30)$ alt boyutlarının düşük düzeyde Kuralsızlık $(X=2,78)$ ve Soyutlanmışık $(\bar{X}=2,61)$ alt boyutlarının ise orta düzeyde ortalamaya sahip olduğu bulgusu elde edilmiştir. Yapılan analizler göz önünde bulundurulduğunda ortaöğretim öğrencilerinin okula yabancılaşma düzeylerinin düşük seviyede olduğu söylenebilir.

Araştırmanın üçüncü alt probleminde ortaöğretim öğrencilerinin okul tükenmişliği ve okula yabancılaşma algıları arasındaki ilişki incelenmiştir. Bu ilişkiye yönelik bulgular aşağıdaki tabloda verilmiştir.

Tablo 4. Okul tükenmişliği ve okula yabancılaşma alt boyutları arasındaki ilişki

\begin{tabular}{ccccccc}
\hline Değişken & $\begin{array}{c}\text { Okul } \\
\text { Tükenmişliği }\end{array}$ & Güçsüzlük & Kuralsızlık & Soyutlanmışık & Anlamsızlık $\begin{array}{c}\text { Okula } \\
\text { yabancılaşma }\end{array}$ \\
\hline $\begin{array}{c}\text { Okul } \\
\text { Tükenmişliği }\end{array}$ & 1 &, $344^{*}$ &, $474^{*}$ &, $418^{*}$ &, $508^{*}$ &, $612^{*}$ \\
\hline
\end{tabular}

$* p<0.01$

Ortaöğretim öğrencilerinin okul tükenmişliği ile okula yabancılaşma ve okula yabancılaşmanın alt boyutları arasında anlamlı bir ilişkinin olup olmadığını belirlemek amacıyla yapılan Pearson Korelasyon analizi sonucunda okul tükenmişliği ile Güçsüzlük ( $r=.344, p<.01)$, Kuralsızlık $(r=.474, p<.01)$, Soyutlanmışlık $(r=.418, p<.01)$, Anlamsızlık $(r=.508, p<.01)$ ve Okula yabancılaşma $(r=.612, p<.01)$ arasında pozitif yönlü anlamlı bir ilişki olduğu sonucuna ulaşılmıştır. Bu sonuç doğrultusunda ortaöğretim öğrencilerinin okul tükenmişliği artıkça okula yabancılaşma düzeylerinin de artacağı söylenebilir. Okul tükenmişliği ile okula yabancılaşma alt boyutları arasındaki ilişkinin yordanmasına yönelik analiz sonuçları aşağıdaki tabloda verilmiştir.

Tablo 5. Ortaöğretim öğrencilerinin okul tükenmişliğinin yordanmasına ilişkin çoklu regresyon analizi sonuçları

\begin{tabular}{llllllll}
\hline Değişken & $\mathbf{B}$ & Standart Hata & $\boldsymbol{\beta}$ & $\mathbf{t}$ & $\mathbf{p}$ & ikili r & Kısmi r \\
\hline Sabit & .704 & .142 & & 4,958 & .000 & - & - \\
Güçsüzlük & .166 & .043 & .170 & 3,822 & .000 & .344 & .197 \\
Kuralıılık & .139 & .046 & .168 & 3,043 & .003 & .474 & .158 \\
Soyutlanmışıık & .232 & .040 & .256 & 5,772 & .000 & .418 & .290 \\
Anlamsızlık & .234 & .048 & .265 & 4,821 & .000 & .508 & .246 \\
\hline $\mathrm{R}=0.616$, & $\mathrm{R}^{2}=0.379$ & & & & & & \\
\hline $\mathrm{F}(4,362)=55,220$ & $\mathrm{p}=.000$ & &
\end{tabular}

Çoklu regresyon analizi sonucunda okula yabancılaşmanın alt boyutları olan güçsüzlük, kuralsızlık, soyutlanmışlık ve anlamsızlığın ortaöğretim öğrencilerinin okul tükenmişliği ile anlamlı bir ilişkiye sahip olduğu tespit edilmiştir, $\left(R=0.616, R^{2}=0.379, p<0.01\right)$. Güçsüzlük, kuralsızlık, soyutlanmışlık ve anlamsızlık alt boyutları okul tükenmişliğinin \%38'ini açıklamaktadır. Regresyon katsayılarının anlamlılı̆ına ilişkin t-testi sonuçları incelendiğinde tüm alt boyutların 
okul tükenmişliği üzerinde anlamlı bir yordayıcı olduğu sonucu elde edilmiştir. Regresyon analizi sonucunda okul tükenmişliğinin yordanmasına ilişkin çoklu regresyon modeli şu şekildedir:

OkulTükenmişliği=0.704+0.166Güçsüzlük+0.139Kuralsıllık+0.232Soyutlanmışlık+0.234Anlamsızlık

Standardize edilmiş ( $\beta$ ) katsayısı ve t değerleri incelendiğinde yordayıcı değişkenlerin okul tükenmişliği üzerindeki göreli önem derecesi anlamsızlık, soyutlanmışlık, güçsüzlük ve kuralsızlıktır.

\section{Sonuç}

Yapılan bu çalışma ortaöğretim öğrencilerinin okul tükenmişliği ve okula yabancılaşma algılarını ve bu her iki algı arasındaki ilişkinin düzeyini belirlemeyi amaçlamıştır. Çalışmanın bu bölümünde elde edilen sonuçlar alanyazında söz konusu konularla ilgili yapılan çalışmaların sonuçları ile karşılaştırılarak tartışılıp öneriler sunulmuştur.

Yapılan analizler sonucunda örnekleme dâhil olan ortaöğretim öğrencilerinin okul tükenmişliği düzeylerinin orta seviyede olduğu alt boyutlarında ise duygusal tükenme alt boyutunun orta düzeyde; duyarsızlaşma ve düşük kişisel başarı alt boyutlarının ise düşük düzeyde olduğu sonucuna ulaşılmıştır. Elde edilen bu sonuç alanyazındaki çalışmaların sonuçları ile benzerlik göstermektedir (Balkıs, Duru, Buluş, \& Duru, 2011; Baş, 2012; Chang, Rand, \& Strunk, 2000; Cushan \& West, 2006; Çapulcuğlu \& Gündüz, 2013; Hu \& Schaufeli, 2009; Kara, 2014; Kutsal, 2009; Lingard, 2007; Polat, 2018; Salmela-Aro vd., 2009; Salmela-Aro \& Upadyaya, 2014; Schaufeli \& Salanova, 2007; Yang, 2004). Ortaöğretim öğrencilerinin üniversite sınavlarına hazırlanmaları, derslerinin yoğun olması, yakın çevrelerinin kendileri üzerindeki yüksek beklentilere sahip olmaları tükenmişlik duyguları yaşamalarını kaçınılmaz kıldığı düşünülmektedir.

Araştırmanın ikinci alt probleminde yapılan analizler doğrultusunda ortaöğretim öğrencilerinin okula yabancılaşma puan ortalamalarının düşük seviyede olduğu tespit edilmiştir. Okula yabancılaşma alt boyutları incelendiğinde Güçsüzlük ve Anlamsızlık alt boyutlarının düşük düzeyde Kuralsızlık ve Soyutlanmışlık alt boyutlarının ise orta düzeyde ortalamaya sahip olduğu bulgusu elde edilmiştir. Elde edilen bu bulgu alanyazında yapılan çalışmaların sonuçlarıyla paralellik göstermektedir (Arastaman, 2009; Coşkun \& Altay, 2009, Katıtaş, 2012; Polat, 2018). Bu sonucun tersine alanyazında ortaöğretim öğrencilerinin okula yabancılaşma düzeylerinim orta veya yüksek seviyede olduğu bulgusu elde edilen çalışmalar da mevcuttur (Ayık, Uzun, Ataş, \& Yücel, 2015; Bayhan, 1995; Çiftçi, 2009; Gedik \& Cömert, 2018; Türk, 2010).

Ortaöğretim öğrencilerinin okul tükenmişliği ile okula yabancılaşma ve okula yabancılaşmanın alt boyutları arasında anlamlı bir ilişkinin olup olmadığını belirlemek amacıyla yapılan analizler sonucunda okul tükenmişliği ile Güçsüzlük, Kuralsılık, Soyutlanmışlık, Anlamsızlık ve Okula yabancılaşma arasında pozitif yönlü anlamlı bir ilişki olduğu sonucuna ulaşılmıştır. Çoklu regresyon analizi sonucunda ise okula yabancılaşmanın alt boyutları olan Güçsüzlük, Kuralsızlık, Soyutlanmışlık ve Anlamsızlığın ortaöğretim öğrencilerinin okul tükenmişliği ile anlamlı bir ilişkiye sahip olduğu tespit edilmiştir. Güçsüzlük, kuralsızlık, soyutlanmışık ve anlamsızlık alt boyutları okul tükenmişliğinin \%38'ini açıklamaktadır. Okula yabancılaşma okul tükenmişliğinin anlamlı bir yordayıcısı olduğu söylenebilir. Başka bir ifade ile ortaöğretim öğrencilerinin okul tükenmişliği artıkça okula yabancılaşma düzeylerinin de artacağı söylenebilir. Bu sonuç alanyazında yapılan diğer çalışmaların sonuçları ile uyumludur (Atik, 2016; Coşkun \& Altay, 2009; Katıtaş, 2012; Lin \& Huang, 2012; Polat, 2018; Tümkaya, 2016).

Sonuç olarak okula yabancılaşma ve okul tükenmişliği okulda öğrencilerin akademik başarılarının artmasında ve kişisel gelişimlerinin sağlanmasında bir engel olarak görülmektedir. Eğitimin çıktısı olarak görülen öğrencilerin daha nitelikli bir halde yetişebilmeleri için öğrencilerin yaşadıkları yabancılaşma ve tükenmişlik sendromlarının kontrol altına alınması gerekmektedir.

\section{5. Öneriler}

Yapılan bu çalışmada ortaöğretim öğrencilerinin okula yabancılaşma ve okul tükenmişliği algıları arasında ilişki incelenmiştir. Çalışmada elde edilen sonuçlar doğrultusunda araştırmacılara ve uygulamacılara şu öneriler sunulmuştur:

1. Çalışmada okula yabancılaşma okul tükenmişliğinin önemli bir yordayıcısı olduğu saptanmıştır. Bu konuda okul yöneticileri ve öğretmenlerin öğrencileri okula kazandıracak etkinlikler tasarlamaları önemlidir. Özellikle öğrencilerin okulda öğrendikleri bilgileri günlük hayata aktaracak etkinliklerin sayısı artırılmalıdır.

2. Ortaöğretim öğrencilerinin okula yabancılaşması ve okul tükenmişlik düzeylerinin azaltılmasına yönelik eğitim programları hazırlanabilir. 


\section{Kaynakça}

Arastaman, G. (2009). Lise birinci sınıf öğrencilerinin okula bağlılık (school engagement) durumlarına ilişkin öğrenci, öğretmen ve yöneticilerin görüşleri. Pamukkale Üniversitesi Eğitim Fakültesi Dergisi, 26, 102-112

Atik, S. (2016). Akademik başarının yordayıcıları olarak öğretmene güven, okula karşı tutum, okula yabancılaşma ve okul tükenmişliği. Doktora Tezi. İnönü Üniversitesi, Eğitim Bilimleri Enstitüsü, Malatya.

Ayık, A., Uzun, T. Ataş, Ö., \& Yücel, E. (2015). Öğrencilerin genel sinizm tutumları ve okula yabancılaşma algıları arasındaki ilişkilerin incelenmesi. The Journal of Academic Social Science Studies, 39, 491-508.

Aypay, A., \& Eryılmaz, A. (2011). Lise öğrencilerinin öznel iyi oluşları ve okul tükenmişliği arasındaki ilişkiler. International Online Journal of Educational Sciences, 3(1), 181-199.

Balkıs, M., Duru, E., Buluş, M., \& Duru, S. (2011). Tükenmişliğin öğretmen adayları arasındaki yaygınlığı, demografik değişkenler ve akademik başarı ile ilişkisi. Pamukkale Üniversitesi Eğitim Fakültesi Dergisi, 29, 151-165.

Barnett, M. D., \& Flores, J. (2016). Narcissus, exhausted: Self-compassion mediates the relationship between narcissism and school burnout. Personality and Individual Differences, 97, 102-108.

Baş, G. (2012). İlköğretim öğrencilerinde tükenmişlik: farklı değişkenler açısından bir değerlendirme. Journal of European Education, 2, 31-46.

Bayhan, V. (1995). Üniversite gençliğinde anomi ve yabancılaşma. Doktora Tezi, İnönü Üniversitesi Sosyal Bilimler Enstitüsü, Malatya.

Büyüköztürk, Ş., Kılıç-Çakmak, E., Akgün, Ö.E., Karadeniz, Ş., \& Demirel, F. (2010). Bilimsel araştırma yöntemleri. Ankara: Pegem Akademi.

Chang, E. C., Rand, K. L., \& Strunk, D. R. (2000). Optimism and risk for job burnout among working college students: Stress as a mediator. Personality and Individual Differences, 29, 255-263.

Coşkun, Y., \& Altay, C. A. (2009). Lise öğrencilerinde yabancılaşma ve benlik algısı ilişkisi. Atatürk Eğitim Fakültesi Eğitim Bilimleri Dergisi, 29, 41-56.

Cushman, S., \& West, R. (2006). Precursors to college student burnout: Developing a typology of understanding. Qualitative Research Reports in Communication, 7, 23-31

Çapulcuoğlu, U., \& Gündüz, B. (2013). Öğrenci tükenmişliğini yordamada stresle başaçıkma, sınav kaygısı, akademik yetkinlik ve anne-baba tutumları. Eğitim Bilimleri Araştırmaları Dergisi, 3, 201-218.

Çağlar, Ç. (2012). Öğrenci yabancılaşma ölçeğinin (ÖYÖ) geliştirilmesi. Eğitim ve Bilim, 37(166), 195-205.

Çapri, B., \& Yedigöz-Sönmez, G. (2013). Lise öğrencilerinin tükenmişlik puanlarının sosyo-demografik değişkenler, psikolojik belirtiler ve bağlanma stilleri açısından incelenmesi. International Journal of Human Sciences, 10(2), 195- 218.

Çapulcuoğlu, U. (2012). Öğrenci tükenmişliğini yordamada stresle başaçıkma, sınav kaygısı, akademik yetkinlik ve anne-baba tutumları değişkenlerinin incelenmesi. Yüksek Lisans Tezi, Mersin Üniversitesi, Eğitim Bilimleri Enstitüsü, Mersin.

Çapri, B., Gündüz, B., \& Gökçakan, Z. (2011). Maslach tükenmişlik envanteri-öğrenci formu (mte-öf)'nun Türkçe'ye uyarlaması: Geçerlik ve güvenirlik çalışması. Çukurova Üniversitesi Eğitim Fakültesi Dergisi, 40 (1),134-147.

Çelik, F. (2005). Orta öğretim öğrencilerinin okula yabancılaşma düzeylerinin bazı değişkenler açısından incelenmesi. Yüksek Lisans Tezi. Çukurova Üniversitesi, Adana.

Çiftçi, G. (2009). ilköğretim okullarının bürokratikleşme düzeyi ile öğrenci yabancılaşması arasındaki ilişki. Yüksek Lisans Tezi. Pamukkale Üniversitesi, Sosyal Bilimler Enstitüsü, Denizli.

Duru, E. (1995). Üniversite öğrencilerinin yabancılaşma ve yalnızlık ilişkileri. Yüksek Lisans Tezi. Dokuz Eylül Üniversitesi, Sosyal Bilimler Enstitüsü, İzmir.

Gedik, A., \& Cömert, M. (2018). Ortaöğretim öğrencilerinde okula yabancılaşma düzeyleri. Iğdır Üniversitesi Sosyal Bilimler Dergisi, 15, 475-497. 
Gündüz, B., Çapri, B., \& Gökçakan, Z. (2012). Üniversite öğrencilerinin tükenmişlik düzeylerinin incelenmesi. Dicle Üniversitesi Ziya Gökalp Eğitim Fakültesi Dergisi, 19, 38-55.

Hascher, T., \& Hagenauer, G. (2010). Alienation from school. International Journal of Educational Research, 49(6), 220232.

Hu, Q., \& Schaufeli, W. B. (2009). The factorial validity of the maslach burnout Inventory- student survey in China. Psychological Reports, 105, 394-408.

Huang, Y.C., \& Lin, S.H. (2010). Canonical correlation analysis on life stress and learning burnout of college students in Taiwan. International Electronic Journal of Health Education, 13, 145-155.

Jacobs, S., \& Dodd, D. (2003). Student burnout as a function of personality, social support, and workload. Journal of College Student Development, 44 (3), 291-303

Kara, S. (2014). Lise öğrencilerinde okul tükenmişliği ile psikolojik iyi olma arasındaki ilişkinin çeşitli değişkenler açısından incelenmesi. Yüksek lisans tezi. Sakarya Üniversitesi, Eğitim Bilimleri Enstitüsü, Sakarya.

Karasar, N. (2009). Bilimsel araştırma yöntemi. Ankara: Nobel Yayınevi.

Katıtaş, S. (2012). ilköğretim ikinci kademe öğrencilerinde okula yabancılaşma ve okulu bırakma eğilimi. Yüksek Lisans Tezi. Harran Üniversitesi, Şanlıurfa.

Kiuru, N., Aunola, K., Nurmi J., Leskinen, E., \& Salmela-Aro, K. (2008) Peer group influence and selection in adolescents' school burnout. Merrill Palmer Q, 54:23-55.

Kunkel, R.C, Thompson,J.C., \& Mcelhinney, J.H.(1973). School related alienation perceptions of secondary school students. ED 074 092. 20.05.2019 tarihinde https://files.eric.ed.gov/fulltext/ED074092.pdf adresinden alınmıştır.

Kutsal, D. (2009). Lise Öğrencilerinin Tükenmişliklerinin Incelenmesi. Yüksek lisans tezi. Hacettepe Üniversitesi, Sosyal Bilimler Enstitüsü, Ankara.

Kutsal, D., \& Bilge, F. (2012). Lise öğrencilerinin tükenmişlik ve sosyal destek düzeyleri. Eğitim ve Bilim, 37(164), 283297

Lingard, H. (2007). Conflict between paid work and study: does it Impact upon students' burnout and satisfaction with university life? Journal for Education in the Built Environment, 2(1), 90-109.

Meier, S.F., \& Schmeck, R.R. (1985). The burned-out college student: A descriptive profile. Journal of College Student Personal, 26(1) 63-69.

Maslach, C., \& Leiter, M.P. (2016). Understanding the burnout experience: recent research and its implications for psychiatry. World Psychiatry, 15(2), 103-111.

Nedim-Bal, P., \& Kaya, C. (2017). 6.sınıf öğrencilerinin okul tükenmişliği ile baş etmede çözüm odaklı grupla psikolojik danışmanın etkisi. Uluslararası Sosyal Araştırmalar Dergisi, 10(51), 769-777.

Polat, Ş. (2018). Ortaokul öğrencilerinde okula yabancılaşma ve okul tükenmişliği ilişkisinin incelenmesi. Uludağ Üniversitesi Eğitim Fakültesi Dergisi, 31(1), 257-277.

Rostami, Z., Abedi, M. R., \& Schaufeli, W. B. (2012). Dose interest predicts academic burnout?. Interdisciplinary Journal of Contemporary Research in Business, 3 (9), 877-885.

Salanova, M., Schaufeli, W. B., Martineza, I., \& Breso, E. (2009). How obstacles and facilitators predict academic performance: The mediating role of study burnout and engagement. Anxiety, Stress ve Coping, 23, 53-70.

Salmela-Aro, K., Savolainen, H., \& Holopainen, L. (2009). Depressive symptoms and school burnout during adolescence: Evidence from two cross-lagged longitudinal studies. Journal of Youth and Adolescence, 38, $1316-1327$.

Salmela-Aro, K., Kiuru, N., \& Nurmi, J. E. (2008). The role of educational track in adolescents' school burnout: A longitudinal study. British Journal of Educational Psychology, 78, 663-689.

Salmela-Aro, K., Kiuru, N., Leskinen, E., \& Nurmi, J.-E. (2009). School Burnout Inventory (SBI): Reliability and validity. European Journal of Psychological Assessment, 25(1), 48-57. 
Salmela-Aro, K., \& Upadyaya, K. (2014). Developmental trajectories of school burnout: Evidence from two longitudinal studies. Learning and Individual Differences, 36, 60-68.

Schaufeli, W. B., \& Salanova M. (2007). Efficacy or inefficacy, that's the question: Burnout and work engagement, and their relationships with efficacy beliefs. Anxiety, Stress, and Coping, 20 (2), 177-196.

Schaufeli, W. B., Martinez, I., Marques-Pinto, A., Salanova, M., \& Bakker, A. (2002). Burnout and engagement in university students: A cross-national study. Journal of Cross-cultural Studies, 33, 464-481.

Schulz, L. L., \& Rubel, D. J. (2011). A phenomenology of alienation in high school: The experiences of five male noncompleters. Professional School Counseling, 14(5), 286- 298.

Seçer, I.., Halmatov, S., Veyis, F., \& Ateş, B. (2013). Okul tükenmişlik ölçeğinin Türk kültürüne uyarlanması: Güvenirlik ve geçerlik çalışması. Turkish Journal of Education, 2(2), 16-27.

Sidorkin, A. M. (2004). In the event of learning: alienation and participative thinking in education. Educational Theory, 54(3), 251-262.

Sungur, A. (2013). Ortaöğretim kurumlarında okuyan öğrencilerin okul yurtlarındaki yaşamı ve yabancılaşma. Sosyoloji Alanı Ortaöğretim Öğrencileri Arası Proje Yarışması, Tübitak

Şimşek, H., Abuzar, C., Yegin, i. H., Şimşek, S., \& Demir, A. (2015). Okula yabancılaşma ölçeği. Kırşehir Eğitim Fakültesi Dergisi, 16(4), 309-322.

Tabachnick, B. G. \& Fidell, L. S. (2013). Using multivariate statistics. Boston, Pearson.

Tümkaya, S. (2016). Sınıf öğretmenliği öğrencilerinin tükenmişlik ve yabancılaşma düzeylerinin incelenmesi. Ç.Ü. Sosyal Bilimler Enstitüsü Dergisi, 25(2), 251-268

Türk, F. (2010). Lise öğrencilerinin eğitimde yabancılaşma sorunu: Ankara ili Yenimahalle ilçesi iki genel lise örneği. Yüksek Lisans Tezi, Ankara Üniversitesi, Eğitim Bilimleri Enstitüsü, Ankara.

Türk, T. (2013). Ortaöğretim öğrencilerinde duygusal istismar, disiplin cezaları ve okula yabancılaşma arasındaki ilişkinin incelenmesi. Yüksek Lisans Tezi, İstanbul Üniversitesi, Sosyal Bilimler Enstitüsü, İstanbul.

Warner, B. S., Weist, M. D., \& Krulak, A. (1999). Risk factors for school violence. Urban Education, 34(1), 52- 68

Yang, H. (2004). Factors affecting study burnout and academic achievement in multiple enrolment programs in Taiwan's technical-vocational colleges. International Journal of Educational Development, 24, 283-301.

Yang, H. J., \& Farn, C. K. (2005). An Investigation the factors affecting mis student burnout in technical-vocational college. Computers in Human Behavior, 21, 917-932.

Yiğit, S. (2010). ilköğretim 5., 6., 7. ve 8.sını öğrencilerinin okula yabancılaşma düzeylerinin çeşitli değişkenler açısından incelenmesi. Yüksek Lisans Tezi, Zonguldak Karaelmas Üniversitesi, Sosyal Bilimler Enstitüsü, Zonguldak.

Yüksek, Ö. (2006). Illköğretim 5. Sınıf öğrencilerinin okula yabancılaşma düzeylerine etki eden sosyo- demografik değişkenlerin belirlenmesi. Yüksek Lisans Tezi, Çukurova Üniversitesi, Sosyal Bilimler Enstitüsü: Adana.

Zhang, Y., Gan, Y. Q., \& Zhang, Y. W. (2005). The reliability and validity of MBI-SS and academic characteristics affecting burnout. Chinese Journal of Clinical Psychology, 13, 383-385. 